\title{
Colorectal Sarcomatoid Carcinoma
}

National Cancer Institute

\section{Source}

National Cancer Institute. Colorectal Sarcomatoid Carcinoma. NCI Thesaurus. Code C96494.

A biphasic colorectal carcinoma with a spindle cell, sarcomatoid component. 